\title{
Control of Refining Processes on Mid-Distillates by Near Infrared Spectroscopy
}

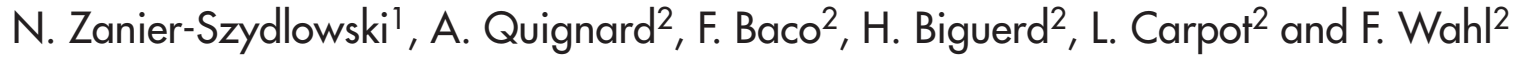 \\ 1 Institut français du pétrole, 1 et 4, avenue de Bois-Préau, 92852 Rueil-Malmaison Cedex - France \\ 2 Institut français du pétrole, CEDI René Navarre, BP 3, 69390 Vernaison - France \\ e-mail: nathalie.zanier@ifp.fr - alain.quignard@ifp.fr - laurence.carpot@ifp.fr - helene.biguerd@ifp.fr - franck.baco@ifp.fr - francois.wahl@ifp.fr
}

\begin{abstract}
Résumé - Suivi de procédés de raffinage sur distillats moyens par spectrométrie proche infrarouge - L'objet de cet article est de démontrer la précision des déterminations physicochimiques réalisées à partir d'équations construites par analyse multivariée de spectres proche infrarouge d'une base dite de calibration. Ce type d'approche permet d'accéder simultanément à différentes propriétés à partir de la mesure d'un seul spectre enregistré en ligne ou de façon ex situ. Les 8 propriétés suivantes sont prédites dans un temps beaucoup plus court que par les méthodes conventionnelles pour des échantillons issus de $l^{\prime}$ hydrotraitement de charge de distillation directe, i.e l'indice de réfraction à $20^{\circ} \mathrm{C}$, la masse volumique à $15^{\circ} \mathrm{C}$, le $\%$ poids d'hydrogène, le $\%$ de carbone aromatique, les $\%$ poids en mono-, di- et total aromatiques et l'indice de cétane. L'efficacité de cette technique a été démontrée pour le suivi détaillé de l'hydrotraitement de gazole.

Mots-clés : spectrométrie proche infrarouge, distillats moyens, analyse multivariée, analyse pétrochimique.
\end{abstract}

\begin{abstract}
Control of Refining Processes on Mid-Distillates by Near Infrared Spectroscopy - The purpose of this paper is to demonstrate the accuracy of physicochemical determinations based on equations calculated by multivariate analysis of near infrared spectra which gives access to simultaneous analyses both on-line and off-line. Detailed results concerning the determination of the refractive index at $20^{\circ} \mathrm{C}$, the density, the weight $\%$ of hydrogen, the \% of aromatic carbon, the weight\% of mono-, di-and total aromatics and the cetane number on mid-distillates are given in a shorter time than using the conventional approach by standardized methods. It is shown that near infrared spectroscopy combined with chemometrics should allow detailed and precise comparisons of the hydrotreatment process efficiencies.
\end{abstract}

Keywords: near infrared spectroscopy, mid-distillates, multivariate analysis, petrochemical analysis.

\section{INTRODUCTION}

The feasability of using near infrared spectroscopy (NIR) [1] combined with multivariate calibration $[2,3]$ to predict simultaneously several chemical and physical properties of petroleum products has already been widely demonstrated [4-8] and makes the incorporation of this technology into real-time process control systems very attractive [9-11]. This technique is now well known to be able to provide rapid, low cost and on-site analyses of very important worldwide commodities such as gasoline [12, 13] and diesel fuel [14] and is as precise as the ASTM (American Society for Testing and Materials) methods. However, moving this analytical technology from the laboratory to the factory or to the process line, has indicated the need to guarantee the performance and reliability of the analyser to avoid a possible expensive misapplication. This is closely linked to a very long and tedious procedure which includes, for each property of interest in a specific validation range, the optimization of the modeling steps, the validation of the 
predicting models including the detection of outliers and the knowledge of the calibration transfer procedures $[15,16]$.

The scope of this paper is to show the accuracy of physicochemical determinations based on equations calculated by multivariate analysis of near infrared spectra and to illustrate the potentialities of NIR spectroscopy for mid-distillates process control. The first property studied is the cetane number $(\mathrm{CN})$. It measures the self-ignition characteristic of the fuel and is determined with a special single-cylinder engine according to the widely accepted ASTM D613-95 [17] standard method. This procedure is time-consuming and requires a large amount of sample (about one liter) as well as skilled operators and complex and expensive instrumentation systems. This represents a very good opportunity for the use of near infrared spectroscopy combined with chemometrics. The NIR correlation has been developed in the 20-65 CN domain which is an expended domain in comparison with the previous studies on the subject. The seven other properties which have been treated for fuels issued from hydrotreatment processes are the refractive index (RI) [17], the density (D15/4) [18] the \% of aromatic carbon $\left(\mathrm{C}_{\mathrm{A}}\right)$ [17] the weight $\%$ of hydrogen $(\% \mathrm{H})$ determined by NMR [19], the weight \% of mono-, di- and total aromatic content by mass spectrometry MS [20] (MonoAros, DiAros, TotalAros). Other properties of interest (i.e. viscosity, total nitrogen, total sulfur, simulated distillation by gas chromatography) have been studied but were not modeled with enough precision compared to the corresponding reference method either for non-linearity behavior or sensitivity problem.

\section{EXPERIMENTAL}

\subsection{NIR Experimental Conditions}

The spectra were recorded on two nitrogen purged Bomem MB160 spectrometers equipped either with an InAs or a DTGS detector, in transmission mode with a resolution of $4 \mathrm{~cm}^{-1}$ using a $2+/-0.02 \mathrm{~mm}$ cell (QX quality) and after a delay of $5 \mathrm{~min}$ with a dry nitrogen flow of $31 / \mathrm{min}$. The Arid-Zone accessory from Bomem was installed on both spectrometers. A maximum absorbance of approximately one absorbance unit was obtained in the wavenumber range $6400-4500 \mathrm{~cm}^{-1}$. Each sample was measured twice randomly with 100 scans per spectrum and the average spectrum was used if the spectral difference between two recordings on the same sample was less than 0.002 absorbance units in the wavenumber range $6400-4500 \mathrm{~cm}^{-1}$. The measurements were carried out at $27.5^{\circ} \mathrm{C}$ with the help of a Peltier cell [21] in a room where the temperature range could vary from $20^{\circ} \mathrm{C}$ to $30^{\circ} \mathrm{C}$.

\subsection{Statistical and Mathematical Tools Used for the Development of the Models}

\subsubsection{Partial Least Square Regression}

Partial Least Square Regression (PLS) is one popular multivariate method for performing quantitative analysis. The mathematics are quite complex and well explained in references $[2,3]$. The ultimate goal is to create a calibration equation or series of equations also called "models" which, applied to spectra of "unknown" samples, will accurately predict the quantities of the components of interest. In order to calculate these equations, a set of "standard" mixtures (calibration data bases) are made or collected which reflect the composition of the "unknowns" as closely as possible, and where all the quantities of components of interest are known. These standards are designed or chosen to span the expected range of compositions in the unknowns and are measured under the same conditions (sampling method, optical pathlength, instrument, temperature, etc.) as the unknowns. This set of spectra and the known quantities of the components in each individual sample form the "calibration" set from which the calibration equations are built. The unknown sample is then measured in the same way and the equations are used to "predict" each property of interest.

The PLS regression operates a spectral decomposition with which each spectrum can be reconstructed with a few $(<10)$ so-called "factors". Each factor is a linear combination of the initial wavelength multiplied by weights. Each spectrum can then be rebuilt by multiplying the factors by "scores" which represent the projection of each spectrum on each factor. The representation of a spectrum is then reduced from many wavelengths to a few scores and allows a simplified mathematical treatment. The criteria for factor selection are described in references [2,3].

PLS regressions were performed with the analysis routine called PLSplus supplied by Galactic Software. The averaged absorbance-type spectra of each sample were mean-centered by the average spectrum of the calibration set and baseline corrected. The predictive power of the models was evaluated by the standard error of prediction (SEP) of the data by crossvalidation with one "left-out" sample. It means that one sample of the "calibration" set which contains $n$ samples is removed and predicted from the calibration equation built with $(n-1)$ other samples. The removed sample is reintroduced into the calibration set. The procedure is repeated with each $n_{i}$ samples. The cross-validation is a so-called "internal-validation" of the calibration models. The predictive power can be also evaluated with an "external" validation samples (validation data bases) with samples which were not used for the determination of the calibration equations.

The spectral ranges were optimised individually for each model to obtain:

- a SEP by cross-validation the nearest to the standard deviation of reproducibility of the reference method; 
- a number of factors less than 6 to avoid model instability;

- the minimum bias in the external validation step;

- a good efficiency of the outlier tests.

\subsubsection{Outlier Detection Tests}

Whatever the algorithm you may use to correlate a signal (the NIR spectrum, here) and a property (the physicochemical properties of interest for hydrotreated gas oils, in this paper), the equation which correlates the signal and the property can be applied in certain conditions, i.e. the chemical composition, the property range, the sample temperature, etc. When one of these conditions is not fulfilled, the unknown sample to analyse has to be declared as an "outlier".

In this work, two tests were used to detect outliers. The first was based on the analysis of the residual spectrum and the second one on the so-called "leverage value":

- The residual spectrum of the unknown was evaluated by a comparison between two variances according to a F-test [22]; the first one is the variance of the unknown sample (calculated from the recorded NIR and the reconstructed NIR spectra of the unknown) and the second one the variance of the calibration set samples (calculated from the recorded NIR and reconstructed NIR spectra of the calibration base). When the associated probability $P(P$ determines the so-called $\alpha$ risk to say whether the two compared variances are different) was greater than 0.95 , the unknown sample was declared to be an outlier.

- The leverage value (leverage) represents the fraction of variance explained by the sample. The leverage limit was generally set to the maximum one encountered with the calibration set samples. Sometimes, it was found necessary to take into account the density of points with the same level of leverage. The leverage limit was decreased to a value corresponding to a high density population. Leverage limits are given for each model shown in Table 1.

TABLE 1

Leverage limit value for the different NIR models

\begin{tabular}{l|c|c|c|c|c|c|c|c}
\hline Model & RI & D15/4 & $\% \mathrm{H}$ & $\begin{array}{c}\text { Tot- } \\
\text { Aros }\end{array}$ & $\begin{array}{c}\text { Mono- } \\
\text { Aros }\end{array}$ & $\begin{array}{c}\text { Di- } \\
\text { Aros }\end{array}$ & $\mathrm{C}_{\mathrm{A}}$ & $\mathrm{CN}$ \\
\hline $\begin{array}{l}\text { Lev. } \\
\text { limit }\end{array}$ & 0.37 & 0.43 & 0.18 & 0.40 & 0.25 & 0.20 & 0.16 & 0.32 \\
\hline
\end{tabular}

RI: refractive index at $20^{\circ} \mathrm{C}$; D15/4: density at $15^{\circ} \mathrm{C}$; $\% \mathrm{H}$ : weight $\%$ hydrogen; $\mathrm{C}_{\mathrm{A}}$ : aromatic carbon; $\mathrm{CN}$ : cetane number.

\subsection{Samples and Data Bases}

The samples were all provided by the CEDI (IFP-Solaize, France).

\subsection{1 "Cetane Number" Model}

The cetane number $(\mathrm{CN})$ model has been developed on an extensive calibration data base (50 samples) which includes kerosene, atmospheric and heavy atmospheric gas oil samples from different crude oils with different origins and from numerous refining processes: 2 HDC GO, 9 HDT GO, 2 HDS GO, 20 SR GO, 7 HDM GO, 4 VB and coker GO, 6 FCC GO (LCO) are included in this base which contains $39 \mathrm{GO}$ and 7 kerosenes. The $\mathrm{CN}$ are in the range 20 to 65 . The distillates classification is illustrated by representing the mean average boiling point ${ }^{1}$ (Fig. 1) determined by the ASTM D86 standard distillation [17] versus the weight $\%$ of aromatics determined by mass spectrometry (MS).

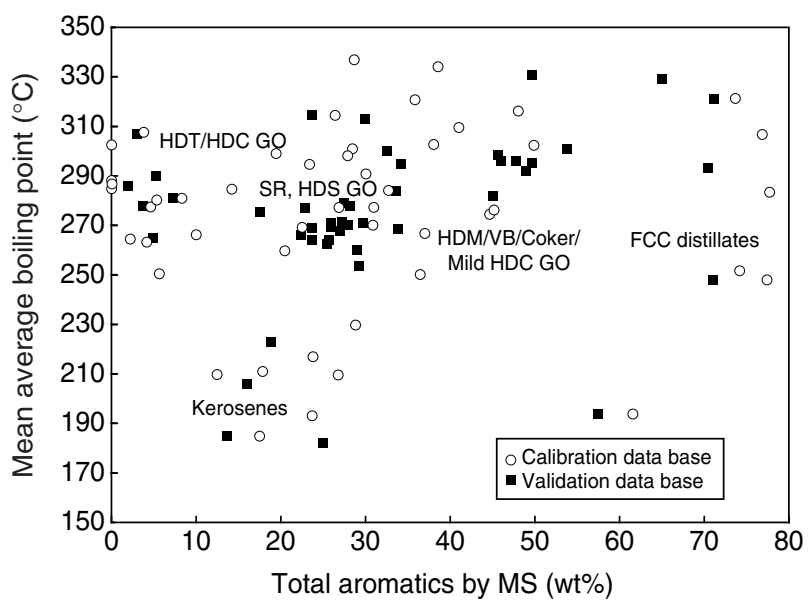

Figure 1

Cetane number versus the total aromatic content for the "CN" calibration and validation data bases.

HDC GO hydrocracked GO at high $\mathrm{H}_{2}$ pressure with highly saturated structures

HDT GO hydrotreated GO: includes hydrodesulfurization at medium and high $\mathrm{H}_{2}$ pressure, as well as deep hydrogenation of aromatics at high $\mathrm{H}_{2}$ pressures

HDS GO hydrodesulfurized GO: includes conventionnal hydrodesulfurization at low $\mathrm{H}_{2}$ pressures

SR GO straight run GO proceeding directly from the topping unit

HDM GO GO proceeding from the hydroconversion (hydrodemetallization) of heavy residues with moderate to high aromatic content (centered on monoaromatics)

$\mathrm{VB}$ and

coker GO highly olefinic GO proceeding from thermal processes, visbreaking and coking, with moderate to high aromatics content

FCC GO GO proceeding from fluid catalytic cracking (also called LCO) with very high aromatic content (centered on diaromatics).
(1) $\left.\left(T_{10}+T_{50}+T_{90}\right) / 3\right)$ in which T10, T50 and T90 respectively represent the boiling point corresponding to $10 \%, 50 \%$ and $90 \%$ distilled. 
The $\mathrm{CN}$ model has been tested with a validation data base containing 47 samples. The $\mathrm{CN}$ values were issued from one measurement at the IFP laboratory. $2 \mathrm{HDC} \mathrm{GO}, 10 \mathrm{HDT}$ GO, 2 HDS GO, 5 commercial GO, 5 SR GO, 4 GO issued from the HDT of vacuum GO, $12 \mathrm{HDM}$ GO, $2 \mathrm{VB}$ and coker GO, 4 FCC GO and 1 blend of SR GO and LCO are included in this base which contains $41 \mathrm{GO}$ and 6 kerosenes. The $\mathrm{CN}$ are in the range 20 to 65 . The distillates classification is illustrating on Figure 1 as for the calibration data base.

\subsubsection{Other Models: RI, D15/4, $\mathrm{C}_{\mathrm{A}} \% \mathrm{H}$, MonoAros, DiAros and TotalAros}

These 7 models were developed on a calibration data base including 75 to 90 gas oil samples according to the property. They were issued from hydrotreatment processes of different feedstocks performed under differents conditions at the CEDIIFP centre. The feedstocks were issued either from straight-run distillation or thermal and thermocatalytic (VB, coking, FCC) processes and were used pure or in mixtures. The samples are classified by representing the mean average boiling point determined by simulated distillation [23] versus the weight $\%$ of aromatics determined by mass spectrometry (Fig. 2).

Thirty eight gas oil samples were used for the validation step (Fig. 2). They were all issued from hydrotreatment processes, from straight run gas oil (SR GO), under different HDS conditions (HDT at low pressure). Most samples are from Arabian heavy crudes, with the exception of three gas oils: two were issued from an Arabian light SR feedstock under HDS (GO 3) and HDT (GO 1) conditions, and one proceeding from a heavy SR gas oil under HDS conditions (GO 2).

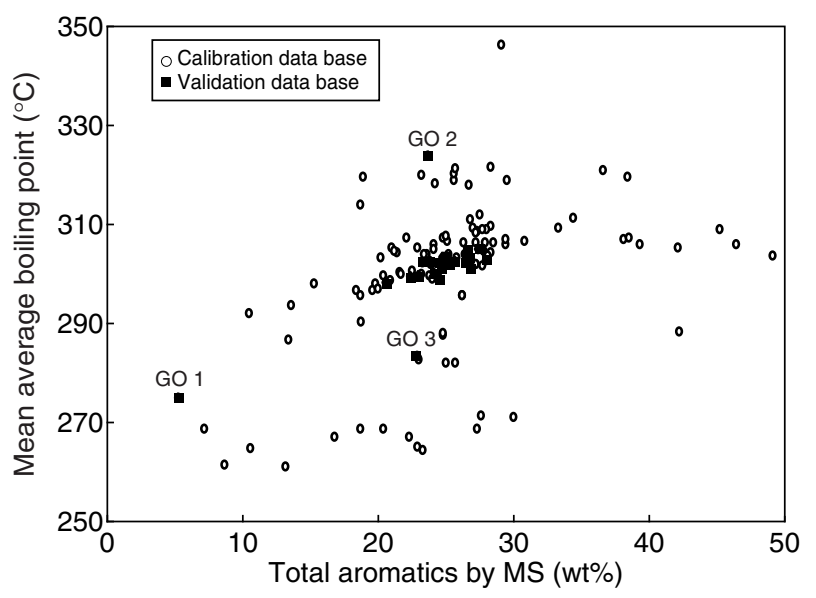

Figure 2

Mean average boiling point versus total aromatic content for the cetane number calibration and validation data bases.

GO 1: one Arabian light HDT GO; GO 2: one heavy HDS GO; GO 3: one Arabian light HDS GO.

\subsection{Precision of the Reference Methods}

In the following, the terms: repeatability $(r)$, reproducibility $(R)$, factor dependent repeatability $(r i)$, factor dependent reproducibility $(R i)$ and standard error $(\sigma)$ are used as defined in references [24, 25].

The precision of the ASTM D613 method (repeatability and reproducibility) for the $\mathrm{CN}$ is given in Table 2 . The

TABLE 2

Precision of the ASTM D613 for cetane number

\begin{tabular}{c|c|c|c|c}
\hline $\begin{array}{c}\text { Average CN } \\
\text { level }\end{array}$ & $\begin{array}{c}\text { Standard deviation } \\
\text { on repeatability: } \sigma r\end{array}$ & $\begin{array}{c}\text { Repeatability } \\
r\end{array}$ & $\begin{array}{c}\text { Standard deviation } \\
\text { on reproducibility: } \sigma R\end{array}$ & $\begin{array}{c}\text { Reproducibility } \\
R\end{array}$ \\
\hline 40 & 0.29 & 0.8 & 1.0 & 2.8 \\
44 & 0.32 & 0.9 & 1.2 & 3.3 \\
48 & 0.32 & 0.9 & 1.4 & 3.8 \\
52 & 0.32 & 0.9 & 1.5 & 4.3 \\
56 & 0.36 & 1.0 & 1.7 & 4.8 \\
\hline
\end{tabular}

TABLE 3

Round Robin on data base: repeatability and reproducibility estimates on cetane number

\begin{tabular}{c|c|c|c|c}
\hline $\begin{array}{c}\text { Average CN } \\
\text { level }\end{array}$ & $\begin{array}{c}\text { Standard deviation } \\
\text { on repeatability: } \sigma r\end{array}$ & $\begin{array}{c}\text { Repeatability } \\
\text { 20-65 }\end{array}$ & $\begin{array}{c}\text { Standard deviation } \\
\text { on reproducibility: } \sigma R\end{array}$ & $\begin{array}{c}\text { Reproducibility } \\
R\end{array}$ \\
\hline 0.76 & 2.2 & 1.4 & 3.9 \\
\hline
\end{tabular}


TABLE 4

Precision of the reference methods

\begin{tabular}{|c|c|c|c|c|c|}
\hline Abbreviation & Reference Method & $\begin{array}{l}\text { Standard dev. on } r: \\
\qquad \sigma r\end{array}$ & $\begin{array}{c}\text { Repeatability } \\
r\end{array}$ & $\begin{array}{l}\text { Standard dev. } \\
\quad \text { on } R: \sigma R\end{array}$ & $\begin{array}{l}\text { Reproducibility } \\
\qquad R\end{array}$ \\
\hline RI & $\begin{array}{l}\text { ASTM D1218 - refractive index and refractive } \\
\text { dispersion of hydrocarbon liquids }\end{array}$ & 0.00007 & 0.0002 & 0.00018 & 0.0005 \\
\hline D15/4 & $\begin{array}{l}\text { ISO EN NF 12185-96: density of liquid } \\
\text { by digital density meter }(\mathrm{kg} / \mathrm{l})\end{array}$ & 0.00007 & 0.0002 & 0.00018 & 0.0005 \\
\hline$\% \mathrm{H}$ & $\begin{array}{l}\text { IFP } 9320 \text { (IFP internal method): hydrogen } \\
\text { content of petroleum products by low } \\
\text { resolution NMR }\end{array}$ & 0.014 & $0.04^{*}$ & - & - \\
\hline $\begin{array}{l}\text { Mono-, Di-, } \\
\text { and TotAros }\end{array}$ & $\begin{array}{l}\text { IFP } 9518 \text { (IFP internal method): mid-distillates } \\
\text { group type analysis by mid-resolution } \\
\text { mass spectrometry }\end{array}$ & & $(0.03 \%$ aros $)+0.3^{*}$ & & $(0.12 \%$ aros $)+0.6^{* *}$ \\
\hline $\mathrm{C}_{\mathrm{A}}$ & $\begin{array}{l}\text { ASTM D3238-90: calculation of } \\
\text { carbon distribution and structural } \\
\text { group analysis of petroleum oils }\end{array}$ & 0.21 & 0.60 & 0.60 & 1.7 \\
\hline
\end{tabular}

* Estimation of within laboratory repeatability from IFP laboratory data.

** Estimation of within laboratory reproducibility from IFP laboratory data.

TABLE 5

Characteristics of the NIR models based on multivariate analysis

\begin{tabular}{|c|c|c|c|c|c|c|}
\hline \multirow[b]{2}{*}{ Property } & \multirow[b]{2}{*}{ Unit } & \multicolumn{5}{|c|}{ NIR model } \\
\hline & & $\begin{array}{c}\text { Spectral } \\
\text { range }\left(\mathrm{cm}^{-1}\right)\end{array}$ & Calibration range & $\begin{array}{l}\text { SEP cross- } \\
\text { validation }\end{array}$ & $\begin{array}{l}\text { Stability } \\
\text { in time* }\end{array}$ & $\begin{array}{c}\text { Number of } \\
\text { factor }\end{array}$ \\
\hline $\begin{array}{c}\text { Refractive } \\
\text { index at } 20^{\circ} \mathrm{C} \\
\text { (RI) }\end{array}$ & & $6050-5850$ & $1.4500-1.4925$ & 0.0004 & 0.0003 & 5 \\
\hline $\begin{array}{l}\text { Density } \\
\text { at } 15^{\circ} \mathrm{C} \\
(\mathrm{D} 15 / 4)\end{array}$ & $\mathrm{kg} / \mathrm{m}^{3}$ & $6050-5850$ & $815-880$ & 0.4 & 0.4 & 6 \\
\hline $\begin{array}{c}\text { Hydrogen } \\
\text { content }(\% \mathrm{H})\end{array}$ & Weight $\%$ & $6400-5600$ & $12.2-14.2$ & 0.016 & 0.01 & 5 \\
\hline $\begin{array}{c}\text { Total } \\
\text { aromatics }\end{array}$ & Weight $\%$ & $6100-5500$ & $5-45$ & 1.6 & 0.1 & 5 \\
\hline Mono-aromatics & Weight $\%$ & $6300-5850$ & $5-30$ & 1.2 & 0.1 & 4 \\
\hline Di-aromatics & Weight $\%$ & $6300-5850$ & $2-20$ & 1 & 0.1 & 2 \\
\hline $\begin{array}{l}\text { Aromatic carbon } \\
\qquad\left(\mathrm{C}_{\mathrm{A}}\right)\end{array}$ & $\%$ & $6100-5600$ & $2.5-25$ & 0.4 & 0.1 & 6 \\
\hline $\begin{array}{l}\text { Cetane number } \\
(\mathrm{CN})\end{array}$ & & $\begin{array}{l}8300-8100 \\
7300-6900 \\
6000-5400\end{array}$ & $20-65$ & 2 & 0.5 & 5 \\
\hline
\end{tabular}

* Stability in time: maximum difference for 10 NIR predictions of the same sample obtained within $4 \mathrm{~h}$. 
relatively poor precision has been confirmed by a Round Robin test including 20 of the $50 \mathrm{GO}$ of the calibration data base by three to five laboratories (Table 3). In this case, the estimated precision has not been found to be dependent on the average $\mathrm{CN}$ level.

The precisions of other reference methods are given in Table 4.

\subsection{NIR Models}

\subsubsection{Characteristics of the NIR Models}

The characteristics of the 8 NIR models are given on Table 5 . The standard errors of prediction (SEP) of the models obtained by cross-validation are of the same order of magnitude as that of the standard deviation on reproducibility of the reference methods (Table 2 to 4 ), except for the refractive index $(R I)$ model.

\subsubsection{Short Term NIR Prediction Stability}

The short term NIR prediction stability for the 8 NIR models has been estimated with 10 NIR measurements over 10 days on a representative HDS GO from Arabian heavy SR feedstock $(\mathrm{CN}=57, \mathrm{D} 15 / 4=0.8331 \mathrm{~kg} / \mathrm{l}, \mathrm{RI}=1.4639$, $\% \mathrm{H}=13.67 \mathrm{wt} \%, \mathrm{C}_{\mathrm{A}}=10.12$, monoaromatics $=17.8 \mathrm{wt} \%$, diaromatics $=4.7 \mathrm{wt} \%$, total aromatics $=23.6 \mathrm{wt} \%$ ). The results are given in Table 6 . The repeatability of the predicted NIR values is comparable to that of the values obtained by the most precise reference methods (RI, D15/4).

\section{TABLE 6}

Short term stability of the NIR prediction for the 8 NIR models estimated on an HDS GO and comparison with the reference methods

\begin{tabular}{l|c|c|c}
\hline $\begin{array}{l}\text { Model/ } \\
\text { Ref. method }\end{array}$ & $\begin{array}{c}\text { NIR lab. } \\
\text { repeatability } \\
r i\end{array}$ & $\begin{array}{c}\text { IFP intra-lab. } \\
\text { repeatability } \\
r i\end{array}$ & $\begin{array}{c}\text { Ref. method } \\
\text { repeatability } \\
r\end{array}$ \\
\hline RI & 0.0002 & 0.0004 & 0.0002 \\
\hline D15/4 (kg/L) & 0.0004 & 0.00015 & 0.0002 \\
\hline $\begin{array}{l}\text { \%H by NMR } \\
\text { (wt\%) }\end{array}$ & 0.01 & 0.04 & n.d. \\
\hline $\begin{array}{l}\text { TotAros by MS } \\
\text { (wt\%) }\end{array}$ & 0.2 & 1.0 & n.d. \\
\hline $\begin{array}{l}\text { MonoAros by MS } \\
\text { (wt\%) }\end{array}$ & 0.1 & 0.8 & n.d. \\
\hline $\begin{array}{l}\text { DiAros by MS } \\
\text { (wt\%) }\end{array}$ & 0.05 & 0.4 & n.d \\
\hline $\mathrm{C}_{\mathrm{A}}$ & 0.05 & 0.6 & 0.6 \\
\hline $\mathrm{CN}$ & 0.5 & 2.0 & 1.0 \\
\hline
\end{tabular}

\section{EVALUATION OF THE PERFORMANCES OF THE NIR MODELS WITH THE CORRESPONDING VALIDATION SETS}

\subsection{Cetane Number (CN)}

The NIR predictions of the $\mathrm{CN}$ are well within the reproducibility limits of the CFR measurement without any bias, as shown on Figure 3. On the 47 tested gas oils, 4 distillates have been found to be outliers: two on leverage, one on the residual spectrum and one on both detection tests. These samples are a heavy FCC gasoline (lev. $=0.41)$, a light LCO (lev. = 0.33), a hydrotreated LCO (LCO HDT) at high $\mathrm{H}_{2}$ pressure $(P>95 \%)$ and a hydrodearomatized LCO (LCO HDA: lev. $=0.41-P>99 \%)$ with a very specific structure ( $80 \%$ of naphthenes, mostly polynaphthenes). This very special sample is the only distillate which has been excluded, both on leverage and residual spectrum outlier tests. It is also the only sample which is not well predicted.

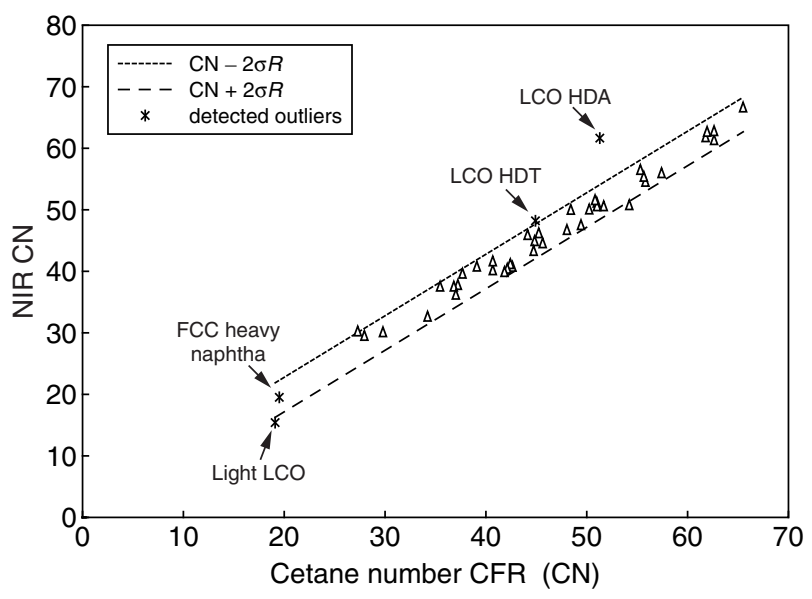

Figure 3

NIR predicted $\mathrm{CN}$ versus the reference cetane number values. The interval of confidence is drawn with reference to the diagonal.

\subsection{Refractive Index (RI)}

NIR predictions of the refractive indices are within the reproducibility limit of the reference method as shown on Figure 4. There is no significant bias and only two outliers: one Arabian light HDT GO called outlier 1 and one HDS heavy GO called outlier 2. The first is detected on the residual spectrum detection test and the second one on residual spectrum and leverage $(\mathrm{lev} .=0.56)$. Nevertheless, both are very well predicted. 


\subsection{Density (D15/4)}

The prediction is not far from the reproducibility limit of the reference method as shown on Figure 5. The two outliers are the same as for the RI model. As expected, the same outliers as for the RI model are detected (lev. $=0.62$ for outlier 1 and lev. $=0.64$ and $P=0.95$ for outlier 2). There is no significant bias.

\subsection{Weight\% of Hydrogen $(\% \mathrm{H})$}

The repeatability of the predictions with the NIR model is equivalent to the intra-laboratory repeatability limit of the reference method as shown on Figure 6. There is a bias of -0.035 which is not significant with regard to the reproducibility of the method. It may induce only an insignificant difference on hydrogen consumption calculated from the hydrogen mass balance between product and feedstock. The outlier 1 and an Arabian light HDS GO called outlier 3 are detected on the leverage test (lev. $=0.33$ and 0.22 respectively).

\section{$2.5 \%$ of Aromatic Carbon $\left(C_{A}\right)$}

The predictions of the NIR models are better than the reproducibility limit and within the repeatability limit of the reference method, as shown on Figure 7, but with a small

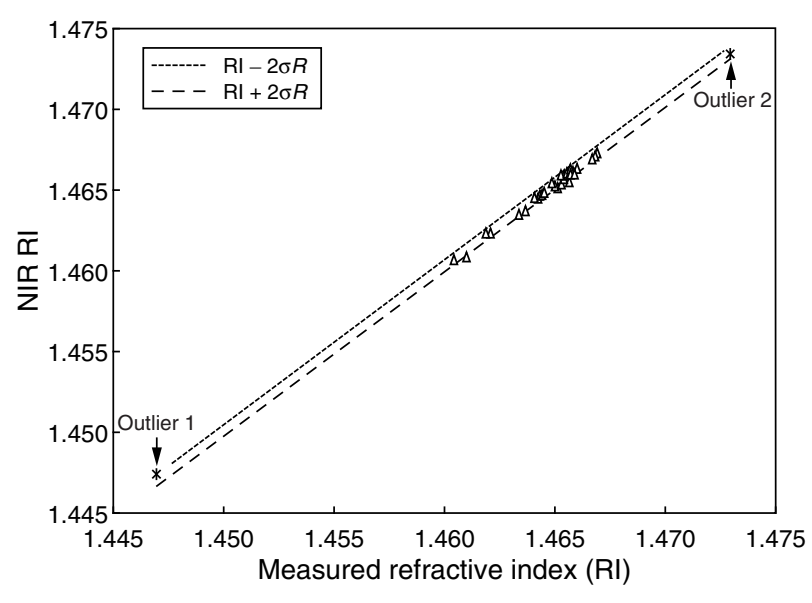

Figure 4

NIR predicted refractive indices versus the reference refractive index. The interval of confidence is drawn with reference to the diagonal. Outlier $1=$ one Arabian light HDT GO and outlier 2 = one HDS heavy GO.

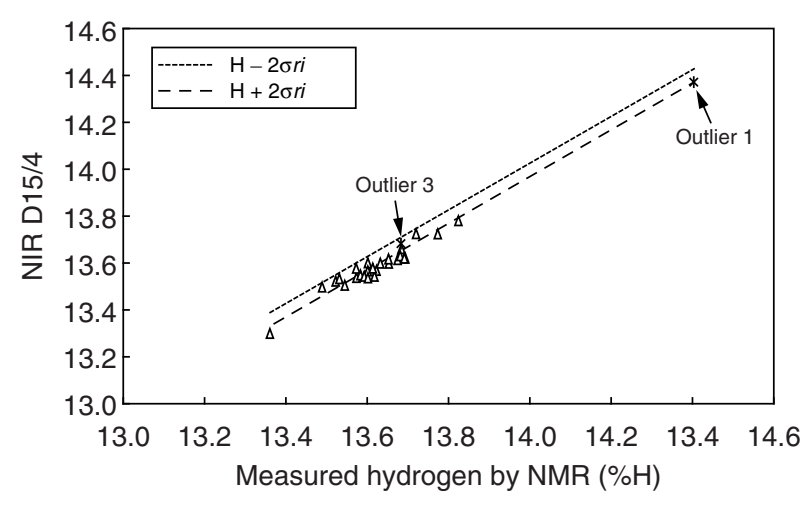

Figure 6

NIR predicted hydrogen content versus the reference hydrogen content values. The interval of confidence is drawn with reference to the diagonal. Outlier $1=$ one Arabian light HDT GO and outlier 3 = one Arabian light HDS GO

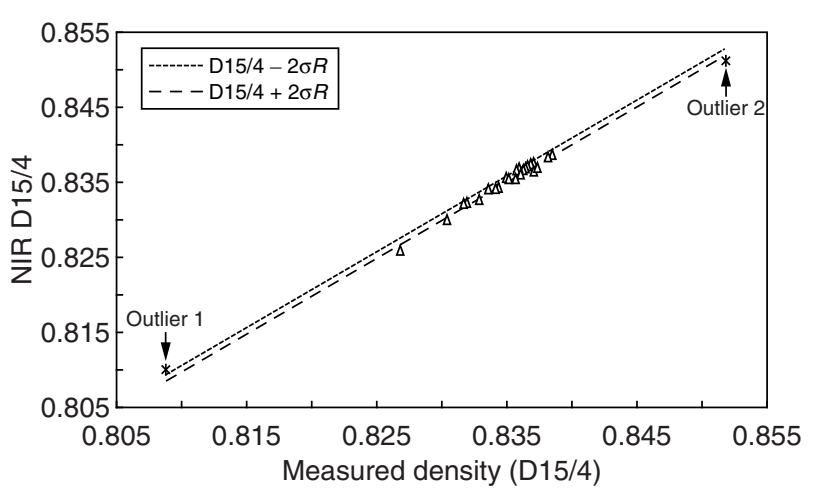

Figure 5

NIR predicted density versus the reference density values. The interval of confidence is drawn with reference to the diagonal. Outlier 1 = one Arabian light HDT GO and outlier 2 = one HDS heavy GO.

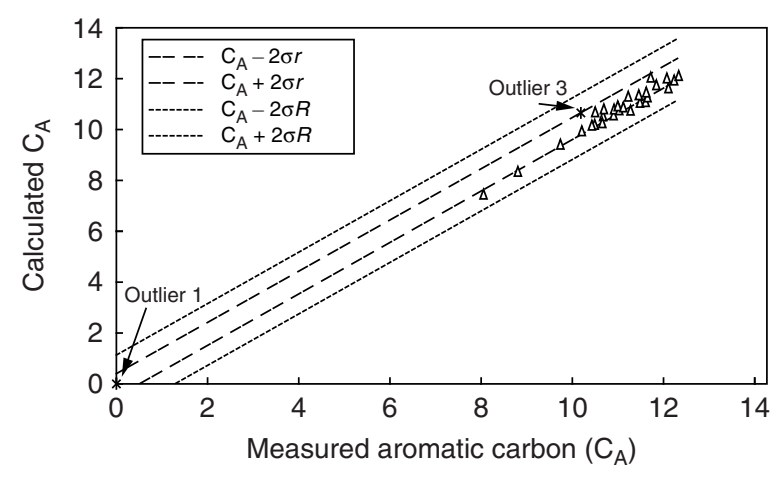

Figure 7

NIR predicted $C_{A}$ versus the reference $C_{A}$ values. The interval of confidence is drawn with reference to the diagonal. Outlier 1 = one Arabian light HDT GO and outlier $3=$ one Arabian light HDS GO. 
bias of -0.5 . As for the hydrogen model, this bias is not significant. We find the same two outliers (lev. $=0.30$ for the outlier 1 and lev. $=0.16$ for the outlier 3 ), as for the previous model showing the correlation between the parameters in the studied domain.

\subsection{Weight\% of Aromatics (Total Aromatics, monoaromatics, Diaromatics)}

The comparison between NIR models and references values are shown on Figures 8 to 10. No outlier has been detected for the 3 models, except for the Arabian light HDT GO (outlier 1) detected on the leverage test (lev. $=0.41$ ) for the monoaromatics model. For the total aromatics model this GO is within, but very close to the leverage limit (lev. $=0.37$ ).

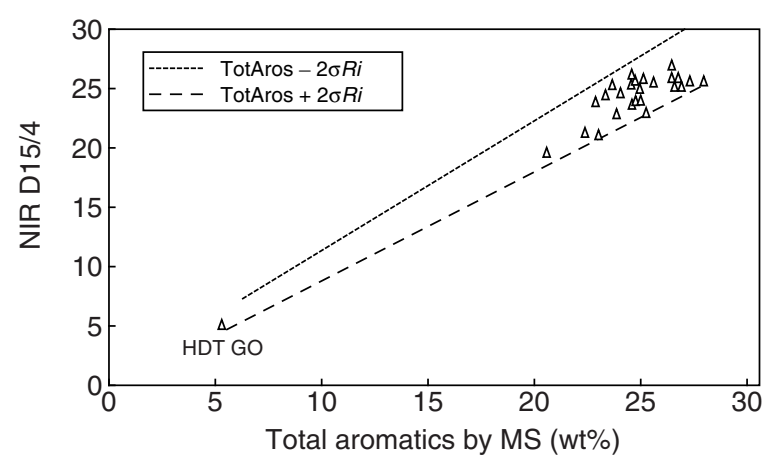

Figure 8

NIR predicted weight $\%$ total aromatic versus the reference weight $\%$ total aromatic. The interval of confidence is drawn with reference to the diagonal.

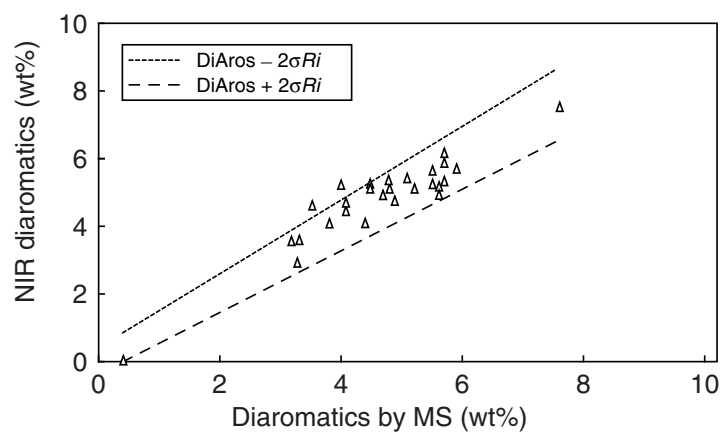

Figure 9

NIR predicted weight $\%$ diaromatic versus the reference weight $\%$ diaromatic. The interval of confidence is drawn with reference to the diagonal.

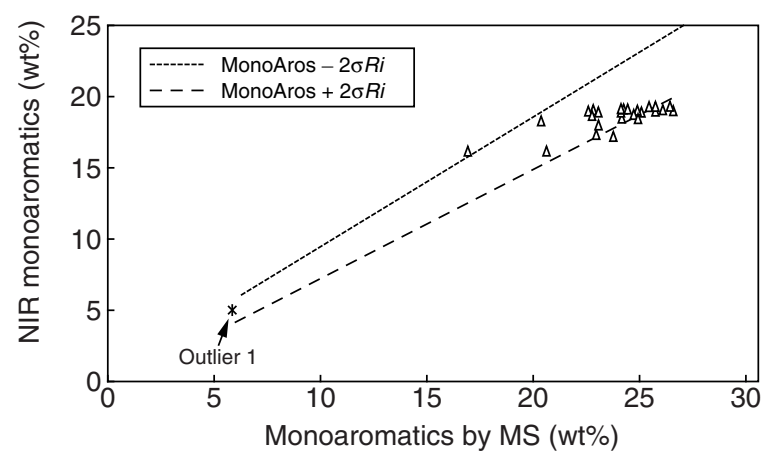

Figure 10

NIR predicted weight $\%$ monoaromatic versus the reference weight $\%$ mono-aromatic. The interval of confidence is drawn with reference to the diagonal. Outlier $1=$ one Arabian light HDT GO.

We can see that the predicted values with the three NIR models are within the intra-laboratory reproducibility limit of the MS method except for some few samples which are close to the reproducibility limit. The low precision on the predicted values compared to the other predicted properties is due to the tight aromatics range described by the samples and the reproducibility of the MS results that is about 10 relative $\%$ at the studied level.

\section{POTENTIALITIES OF THE NIR TECHNIQUE}

\subsection{Effect of Operating Conditions on the Hydrogenation Level of Arabian Heavy HDS Gas Oils}

An extensive comparison has been made with Arabian heavy HDS GO. The hydrotreatment process involves mild operating conditions, without any significant cracking of the feedstock. This is the reason why we may assume that the RI of the HDS GO is a very representative parameter for the global hydrogenation level. The RI has been choosen instead of the hydrogen content by NMR $(\% \mathrm{H})$, which is also a representative parameter, because it is the most accurate analysis related to the hydrogenation. Moreover, the RI is used as a control parameter for the HDS/HDT of middistillates on IFP pilot plants.

A comparison between NIR, UV by Burdett method [26] and MS determination of the weight $\%$ of aromatics has been done. UV analysis has been performed because of its better precision (repeatability and reproducibility) than MS. Nevertheless the UV method shows a bias on aromatics, especially on mono and diaromatics, with respect to the MS method. This bias may partially be explained because each molecule of biphenyl and fluorene series are seen as two monoaromatic cycles using UV and as one diaromatic molecule using MS. 
Results for aromatic contents are shown on Figures 11 to 13. The 3 methods give results consistent with the RI level and the severity of the process, (i.e. the lower the liquid hourly space velocity (LHSV), the lower the aromatics content). The correlation between RI and aromatics content is far better with the UV and NIR methods than from MS results. The total aromatic content can be estimated to $\pm 0.6 \%$ from NIR data, at $\pm 0.8 \%$ from UV data and $\pm 2 \%$ from MS data. Regarding the overall range between 20 to $28 \%$ aromatics, we can assume that the only analytical methods which can be used for an accurate monitoring of the hydrogenation of aromatics are based on the UV and NIR techniques. Results show an equilibrium at the highest LHSV between monoaromatics generated by the hydrogenation of polyaromatics and monoaromatics disappearing by direct hydrogenation. At the lowest LHSV, the hydrogenation conditions are severe enough to shift the global reaction towards a decrease of monoaromatics.

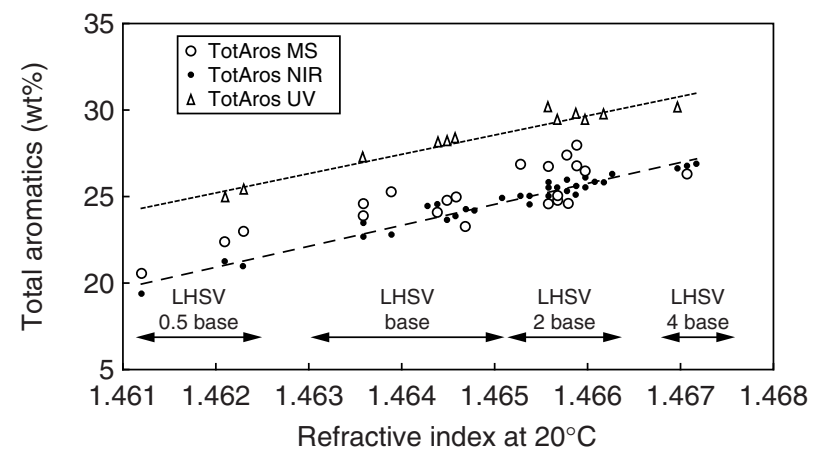

Figure 11

Correlation between the weight $\%$ total aromatic (MS) and the RI.

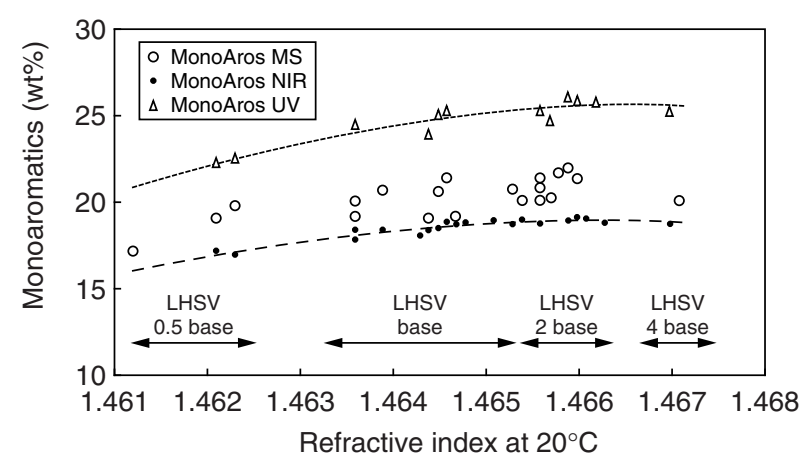

Figure 12

Correlation between the weight $\%$ monoaromatic (MS ) and the RI.

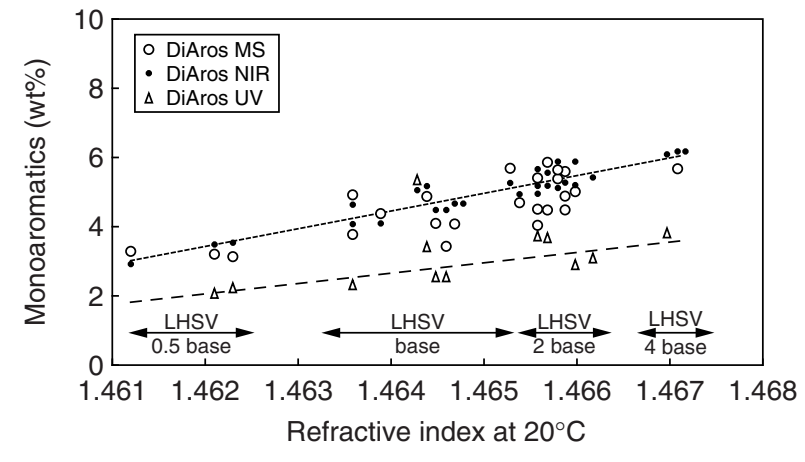

Figure 13

Correlation between the weight $\%$ diaromatic (MS) and the RI.

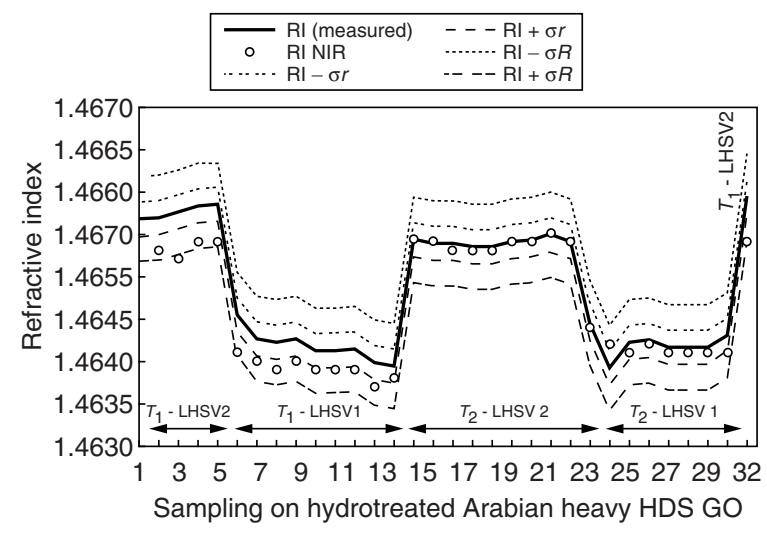

Figure 14

NIR off-line control of HDS pilot plant with the NIR predicted RI.

From all these results, it may be concluded that NIR values are very close to the reference MS values, while the former are much more precise. NIR results are as precise as UV values which are used for detailed and comprehensive comparisons concerning the hydrogenation of aromatics. This makes NIR a very suitable method for comparing hydrotreatment process efficiencies with a high level of sensitivity.

\subsection{Use of NIR for the "Off-Line" Control of Pilot Plants for the HDS of Gas Oils}

The initial development of NIR correlation was essentially based on the "off-line" control of HDS pilot plants for middistillates. This control may concern the RI, the density (D15/4) or other properties. An example is shown for the 
calculated NIR RI values versus the measured ones on 32 samples, for the same feedstock, on the same catalyst, at the same $\mathrm{H}_{2}$ pressure and for 2 levels of temperature and space velocity: $T_{1}, T_{2}, \mathrm{LHSV}_{1}$ and $\mathrm{LHSV}_{2}$. This example can be easily extended to the other properties: density, aromatic carbon, hydrogen content, mono-, di- or total aromatics or $\mathrm{CN}$.

Results are presented on Figure 14. The NIR RI is always within the repeatability limit of the reference method, except for the initial points. Both measured and calculated values are very consistent with the operating conditions.

This shows that NIR results are very accurate and well adapted to autocontrol. In the next future, this type of measurement could be made "on-line" to give access to real-time control.

\section{CONCLUSION}

This work has clearly shown the accuracy of physicochemical determinations based on equations deduced by multivariate analysis of near infrared spectra for the following properties: the refractive index at $20^{\circ} \mathrm{C}$, the density at $15^{\circ} \mathrm{C}$, the weight $\%$ hydrogen, the pourcentage of aromatic carbon and the weight \% mono-, di- and total aromatics for hydrotreated gas oils. The precision of NIR predicted values is equal to or better than that of the reference method, demonstrating that near infrared spectroscopy which associates speed and reliability to simultaneous determinations, is a very powerful tool for process control which allows a detailed and accurate comparison of the efficiency of hydrotreatment processes on mid-distillates. The use of NIR for the analysis of hydrotreated gas oils will decrease the total time of analysis, while assuming an excellent long term precision and could be extended on-line. The presented work has been restricted to hydrotreated gas oils, but this approach could be extended to other refining processes, such as heavy feedstock hydrotreatment, hydrocracking, fluid catalytic cracking (FCC), etc.

As far as the cetane number is concerned, the NIR model has been developed and validated on an extensive $\mathrm{CN}$ domain from 20 to 65 on any type of mid-distillates, showing that it could advantageously replace the time and sample consuming reference method based on CFR engine tests, with much precise results.

\section{ACKNOWLEDGMENTS}

The authors would like to thank Michel Dorbon and Stephane Kressmann from the Development Division, Anne Fafet, Philibert Herrada, Marcel Brunel, Jean Moutarde from the Analytical Division and Jean-Marc Debadts from the Engine Department (IFP) for their contribution to the project.

\section{REFERENCES}

1 Duncan, J.L. (1991) Spectrochimica Acta, 1 (47A), 1-27.

2 Martens, H. and Naes, T. (1989) Multivariate Calibration, John Wiley and Sons, Chichester, 250.

3 Haaland, D.M. and Thomas, E.V. (1988) Anal. Chem., 60, 11, 1193-1202.

4 Foulk, S.J. and DeSimas, B.E. (1990) Process Control and Quality, 2, 69-70.

5 Kelly, J.J., Barlow, C.H., Jinguji, T.M. and Callis, J.B. (1989) Anal. Chem., 61, 313-320.

6 Swarin, S.J. and Drumm, C.A. (1992) Spectroscopy, 7, 7, 42-49.

7 Lysaght, M.J., Kelly, J.J. and Callis, J.B. (1993) Fuel, 72, 5, 623-631.

8 Honigs, D.E., Hirschfeld, T.B. and Hieftje, G.M. (1985) Anal. Chem, 57, 443-445.

9 Espinosa, A., Lambert, D. and Valleur, M. (1995) Hydrocarbon Processing, 86-92.

10 Mackison, R., Brinkwoth, S.J., Belchamber, R.M., Aries, R.E., Cutler, D.J., Deeley, C. and Mould, H.M. (1992) Applied Spectroscopy, 46, 6, 1020-1024.

11 Parisi, A.F., Nogueiras, L. and Prieto, H. (1990) Analytica Chimica Acta, 38, 95-100.

12 Ichikawa, M., Nonaka, N., Takada, I. and Ishimori, S. (1992) Applied Spectroscopy, 46, 6.

13 Kelly, J.J. and Callis, J.B. (1990) Anal. Chem., 62, 1444-1451.

14 Parisi, A.F., Nogueiras, L. and Prieto, H. (1990) Analytica Chimica Acta, 238, 95-100.

15 Shenk, J.S. and Westerhaus, M.O. (1993) NIR News, 4, 5, 13.

16 Wang, Y., Veltkamp, D.L. and Kowalski, R.B. (1991) Anal. Chem., 63, 2750.

17 ASTM (American Society for Testing and Materials), 0501, 0502, 0504 Philadelphia (1998).

18 Petroleum Product and Lubricant, ISO International Organisation for Standardisation (1996), ISO EN NF 12185-96.

19 Gautier, S. and Quignard, A. (1995) Revue de l'Institut français du pétrole, Éditions Technip, 50, 2.

20 Castex, H., Boulet, R., Juguin, J. and Lepinasse, A. (1983) Revue de l'Institut français du pétrole, Éditions Technip, 38, 4.

21 Hoffmann, U. and Zanier-Szydlowski N. (1999) Journal of Near Infrared Spectroscopy, 7, 33-45.

22 Saporta, G. (1990) Probabilités-Analyse de données et Statistiques, Éditions Technip, 488.

23 Durand, J.P., Bré, A, Béboulène, J.J., Ducrozet, A. and Carbonneaux, S. (1997) Capillary Chromatography and Electrophoresis. Proceedings of 19th International Symposium, Wintergreen, 204-205.

24 Statistical methods, ISO Standards, Handbook 3, International Organisation for Standardisation, 3rd ed., (1989).

25 International Organisation for Standardisation, ISO/DIS 5725-1 to 3, Drafts Versions (1994).

26 Burdett, R.A., Taylor, L.W. and Jones, L.C. (1954) (Pub. 1955) Journal of Molecular Spectroscopy. Rept. Conf, Inst. Petroleum, London, 30-41.

Final manuscript received in June 1999 